\title{
Correction to: Transcriptome analysis of the irregular shape of shoot apical meristem in dt (duo tou) mutant of Brassica napus L.
}

\author{
Ke-Ming Zhu • Shuo Xu • Kai-Xia Li • Sheng Chen • \\ Sundus Zafar • Wei Cao - Zheng Wang • Li-Na Ding • \\ Yan-Hua Yang • Yao-Ming Li • Xiao-Li Tan
}

Published online: 25 April 2019

(C) The Author(s) 2019

\section{Correction to: Molecular Breeding \\ https://doi.org/10.1007/s11032-019-0943-1}

The original version of this article unfortunately, contains error in the article title.

The correct article title is presented above.

Page 2, last paragraph, line 8: the term "duo tou" has been corrected in the last paragraph of Introduction section.

Publisher's note Springer Nature remains neutral with regard to jurisdictional claims in published maps and institutional affiliations.

The online version of the original article can be found at https://doi.org/10.1007/s11032-019-0943-1

K.-M. Zhu • S. Xu • K.-X. Li • S. Chen - S. Zafar •

W. Cao · Z. Wang · L.-N. Ding · Y.-H. Yang •

X.-L. Tan $(\bowtie)$

Institute of Life Sciences, Jiangsu University, Zhenjiang, China

e-mail: xltan@ujs.edu.cn

K.-M. Zhu

Key Laboratory of Biology and Genetic Improvement of Oil

Crops, Ministry of Agriculture, Wuhan, China

Y.-M. Li

Institute of Agricultural Engineering, Jiangsu University,

Zhenjiang, China 